\title{
Vector Control System of Induction Motor
}

\author{
Based on Fuzzy Control Method
}

\author{
Haobin Zhou, Bo Long \& Binggang Cao \\ School of Mechatronic Engineering \\ Xi'an JiaoTong University, Xi'an 710049, China \\ E-mail: hbzhou@xsyu.edu.cn
}

\begin{abstract}
Aiming at non-linear model of multivariable induction motor, traditional PI method is hard to achieve satisfactory control purpose. Fuzzy control can carry the real-time control on system without the accurate mathematical model of induction motor. This paper elaborates induction motor vector control system and the basic principle of the fuzzy PI, making use of fuzzy reasoning, automatically adjusting the controller's parameters. Simulation results prove that fuzzy PI controller is superior to traditional PI controller in the aspect of response speed, steady state accuracy and disturbance attenuation.
\end{abstract}

Keywords: Fuzzy control, Vector control, Adjustment parameter

\section{Introduction}

PI control algorithm is simple, realized easily, used in traditional induction motor speed regulating system usually. With the demand of save energy performance and technical and economic target of speed regulating system, PI control have some limitation. For complex model of induction motor, the parameter of the controller is hard auto adjust to adapt outside conditional variety, making the control of motor inaccuracy. To have better adaptability, realize the automatic adjustment of the controller parameter, can adopt the method of the fuzzy control theories. The fuzzy control can realize the automatic adjustment of the control parameter, with strong adaptability and good speed governing. This paper apply vector control method on induction motor, use the decoupling of rotor flux linkage and torque, practice a continuous control, comparatively width speed governing scope. Electric current loop use space vector pulse width modulation, and design a kind of controller of self- adaptation fuzzy control, proceed simulation study through Matlab/Simulink, carry on contrast with traditional PI controller.

\section{Vector control system}

\subsection{Induction motor model}

Dynamic model of induction motor is a high, nonlinear, close coupled and multivariable system. Take forward of voltage, current, flux linkage of each winding as motor routine and right-hand screw rule. At this time, mathematical model of induction motor is constitute by voltage equation, flux linkage equation, torque equation of two-phase arbitrary revolution coordinate as follows:

(1) voltage equation

$$
\left[\begin{array}{l}
u_{s d} \\
u_{s} \\
u_{n d} \\
u_{m}
\end{array}\right]=\left[\begin{array}{cccc}
R_{s}+L_{s} p & -\omega_{c} L_{s} & L_{m} p & -\omega_{c} L_{m} \\
\omega_{c} L_{s} & R_{s}+L_{s} p & \omega_{c} L_{m} & L_{m} p \\
L_{m} p & -\omega_{s} L_{m} & R_{r}+L_{r} p & -\omega_{s} L_{r} \\
\omega_{s} L_{m} & L_{m} p & \omega_{s} L_{r} & R_{r}+L_{r} p
\end{array}\right]\left[\begin{array}{c}
i_{s d} \\
i_{s t} \\
i_{r d} \\
i_{m u}
\end{array}\right]
$$

(2) flux linkage equation

$$
\left\{\begin{array}{l}
\psi_{s d}=L_{s} i_{s d}+L_{m} i_{r d} \\
\psi_{s q}=L_{s s} i_{s q}+L_{m} i_{r q} \\
\psi_{r d}=L_{m} i_{s d}+L_{r} i_{r d} \\
\psi_{r q}=L_{m} i_{s q}+L_{r} i_{r q}
\end{array}\right.
$$

(3) electromagnetic torque equation 


$$
T_{e}=n_{p} L_{m}\left(i_{s q} i_{r d}-i_{s d} i_{r q}\right)
$$

\subsection{Vector principle}

The basic principle of vector control is to simulate torque control rule of direct current motor in general three-phase AC motor, stator current vector is decomposed to field current component that generate magnetic flux and torque current component that generate torque, make them orthogonal and arm s length sale, and adjust independent. So, torque control of AC motor is similar to DC motor in principle. The key of vector control is to control amplitude and spatial location (frequency and phase).

In antecedent dynamic model analysis, as to synchronous revolution coordinate, $\omega_{d q s}=\omega_{1}, \omega_{d q r}=\omega_{1}-\omega=\omega_{s}$, the inner part of rat cage motor is short-circuit, $u_{r d}=u_{r q}=0$ state equations is achieved:

$$
\begin{aligned}
& \frac{d \omega}{d t}=\frac{p_{n}^{2} L_{m}}{L_{r}}\left(i_{s q} \Psi_{r d}-i_{s d} \Psi_{r q}\right)-\frac{p_{n}}{J} T_{L} \\
& \frac{d \Psi_{r d}}{d t}=-\frac{1}{T_{r}} \Psi_{r d}+\left(\omega_{1}-\omega\right) \Psi_{r q}+\frac{L_{m}}{T_{r}} i_{s d} \\
& \frac{d \Psi_{r q}}{d t}=-\frac{1}{T_{r}} \Psi_{r q}+\left(\omega_{1}-\omega\right) \Psi_{r d}+\frac{L_{m}}{T_{r}} i_{s q} \\
& \frac{d i_{s d}}{d t}=\frac{L_{m}}{\sigma L_{s} L_{r} T_{r}} \Psi_{r d}+\frac{L_{m}}{\sigma L_{s} L_{r}} \omega \Psi_{r q}-\frac{R_{s} L_{r}^{2}+R_{r} L_{\mathrm{m}}^{2}}{\sigma L_{s} L_{r}^{2}} i_{s d}+\omega_{1} i_{s q}+\frac{u_{s d}}{\sigma L_{s}} \\
& \frac{d i_{s q}}{d t}=\frac{L_{m}}{\sigma L_{s} L_{r} T_{r}} \Psi_{r q}-\frac{L_{m}}{\sigma L_{s} L_{r}} \omega \Psi_{r d}-\frac{R_{s} L_{\mathrm{r}}^{2}+R_{r} L_{\mathrm{m}}^{2}}{\sigma L_{s} L_{r}^{2}} i_{s q}-\omega_{i} i_{s d}+\frac{u_{s d}}{\sigma L_{s}}
\end{aligned}
$$

In the equation: $S$-motor leakage coefficient, $\sigma=1-L_{m}^{2} / L_{s} L_{r}, T_{r}$-rotor electromagnetic time constant. $T_{r}=L_{r} / R_{r}$

If daxis is taken as direction of whole flux linkage vector, anti-clockwise 90 is q axis, it against to vector, named $\mathrm{T}$ axis, this two phase synchronous revolution coordinate is based on field orientation coordinate. $\mathrm{M}$ axis is rotor field orientation, $\mathrm{T}$ axis is torque control component. Like DC motor, it control individual field current and torque current so that control torque. So, $\Psi_{r d}=\Psi_{r m}=\Psi_{r}, \Psi_{r q}=\Psi_{r t}=0, \dot{\Psi}_{r t}=0$, state equations substituted is given:

$$
\begin{aligned}
& \omega_{s l}=L_{m} i_{s t} / T_{r} \psi_{r} \\
& i_{s m}=\left(T_{r} p+1\right) \psi_{r} / L_{m}
\end{aligned}
$$

It can be seen, rotor field is generated by state current having no relation to torque component, speak from this meaning, field excitation component and torque component of state current is decoupling.

The above formula still expresses that both are first-order inertia link, time constan is rotor flux field time constant, when field excitation $i_{s m}$ happen to change suddenly, the change of $\Psi_{r}$ is objected by field excitation inertia, seeing from this, inertial function of DC motor field-winding is same to the $\Psi_{r}$. Mathematical model is described as following structural style.

\section{Fuzzy PI controller design}

Under the circumstance of nonlinear and parameter time- varying object controlled, accurate model can not be given. Although traditional PID control is simple, controlling result better, it can not solve the circumstance that model parameter occur variety, moreover, in practical spot, because of being subjected to parameter setting, traditional PID parameter setted is not good, its performance is not quite good, be badly to the adaptability. So, according to complex circumstance appllied and the control request of high-performance, having an urgent request to PID parameter self-setted, fuzzy control to PID setted is a good solution.

\subsection{Fuzzy PI principle}

Fuzzy control is computer intelligent control based on fuzzy set theory, fuzzy language, fuzzy logical-inference, its basic idea is presented by famous professor named L.A.Zadeh in California university in America, who achieved the great success in fuzzy control theory and application study through development of many years.

\subsection{Fuzzy PI parameter setted}

Fuzzy self adapting controller has many kind of structural style at the present time, but their operating principle is same to each other. Fuzzy self adapting controller take error e and error alteration ec as an input, amend parameter at a real time using fuzzy control regulation, these constitute fuzzy self adapting controller.

PID parameter fuzzy self adapting is to find fuzzy relationship of three parameter, e and ec, check e and ec continuously in service, according to fuzzy control principle amending three parameter in real time, meeting the different need of controlled parameter in different time, making object controlled having good dynamic and static character.

The core of PID controller design that parameter fuzzy self-adapting is to create suitable fuzzy regulation, see figure 1, 
figure 2, figure 3 individually. At the present, the building of fuzzy regulation is achieved by generalizing experience of operation crews, analysing closed loop response of system, and using method of trial and error through many simulation test.

Establish fuzzy controller inferenced by Mamdani of 1 two-input and three-output using figure windows editor, supposed that input and output is $(-3,3)$,corresponding language value is negative big(NB),negative middle(NM), negative small(NS), zero(Z), positive small(PS), positive middle(PM), positive big (PB), all the degree of membership function of input and output variance are trimf, see figure 2.fuzzy regulation table of Kp see Table 1, fuzzy regulation table of Ki see Table 2,fuzzy regulation table of Kd see Table 3.

\section{Simulation result}

Simulation curve diagram is from figure 4 to figure 6 . Figure 3 and figure 4 express individually that speed response curve of fuzzy PI and PI with a speed code valuation equal to $120 \mathrm{rpm} / \mathrm{min}$, rotational speed is zero at initial state, when time is equal to 0.5 second. Figure 5 and figure 6 express individually that torque response curve of fuzzy PI and PI with a torque code valuation equal to $150 \mathrm{~N} . \mathrm{m}$, rotational speed is zero at initial state, when time is equal to 1 second.

See from simulation result, with initial code valuation, fuzzy PI controller is better than traditional PI controller in speed response and overshoot suppression. When there is some load torque, the former is very excellent in against-interference ability and robust is strong. Under the circumstance of adding code valuation, fuzzy PI controller is superior to traditional PI controller in speed response and steady-state error, which meet the design request.

\section{Conclusion}

Aiming at the characteristic of induction motor with higher order, nonlinear, closed linkage, adopt vector control system according to rotor field orientation control method, integrate fuzzy and PI these two algorithm, design a kind of self-adapting fuzzy controller, proceed simulation test using fuzzy tool in Matlab, compare to traditional PI controller, test express that fuzzy PI controller is superior to traditional PI controller in speed response, steady-state accuracy and against-inference.

\section{References}

A. Visioli. (2001). Tuning of PI controllers with fuzzy logic[J].IEEE Proc-Control Theory, 2001, 148(1): 69 81. Chen, boshi. (2005). AC speed system[M]. Beijing: Machinery Industry Press, 2005.

Driankov, D.H.Hellendoorn, M.Reinfrank. (1993). An Introduction to Fuzzy Control, Springervrelag, Berlin.1993.

Edson, Bim. (2001). Fuzzy Optimization for Rotor Constant Identification of an Indirect FOC Induction Motor Drive. [J]IEEE Transactions on Industrial Electronics, 2001, 48 (6): 1293 1295.

Karr, C L, etal. (1993). Fuzzy control of PH using genetic algorithms.IEEE Trans.on Fuzzy Systems, 1993, 1. (1) $46 \sim 53$.

L. A. Zadeh. (1968). Fuzzy Algorithms [J].Information and Control, 1968 (12): 28 30.

L.A. Zadeh. (1968). Fuzzy Algorithms [J]. Information and Control, 1968, 12.

Lin, C. T. (1994). Neural Fuzzy Control Systems with Structure and Parameter Learning,World Scientific.Singapore, 1994.

Wen, xin, Zhou, lu, (2001). MATLAB toolbox Fuzzy Logic Analysis and Application[M].beijing: Beijing Science Press, 2001.

Yi, jigai, Hou, yuanbin. (2004). Intelligent Control Technology(Fifth Edition)[M].beijing: Beijing Industrial University Press, 2004.

Table 1. fuzzy regulation table of $\mathrm{Kp}$

\begin{tabular}{cccccccc}
\hline$\Delta \mathrm{kp}$ \\
\hline $\mathrm{e}$
\end{tabular}


Table 2. fuzzy regulation table of $\mathrm{Ki}$

\begin{tabular}{|c|c|c|c|c|c|c|c|}
\hline & NB & $\mathrm{NM}$ & NS & Z & PS & $\mathrm{PM}$ & PB \\
\hline NB & NB & $\mathrm{NB}$ & $\mathrm{NM}$ & NM & NS & $\mathrm{Z}$ & $Z$ \\
\hline NM & NB & NB & NM & NS & NS & Z & Z \\
\hline PS & NB & NM & NS & NS & Z & PS & PS \\
\hline Z & NM & NM & NS & Z & PS & PM & $\mathrm{PM}$ \\
\hline PS & NM & NS & Z & PS & PS & $\mathrm{PM}$ & PB \\
\hline PM & Z & Z & PS & PS & $\mathrm{PM}$ & PB & PB \\
\hline PB & $\mathrm{Z}$ & Z & PS & PM & $\mathrm{PM}$ & PB & PB \\
\hline
\end{tabular}

Table 3. fuzzy regulation table of $\mathrm{Kd}$

\begin{tabular}{llllllll}
\hline$\Delta \mathrm{kd} \backslash$ ec & NB & NM & NS & Z & PS & PM & PB \\
\hline e & & & & & & \\
\hline NB & PS & NS & NB & NB & NB & NM & PS \\
NM & PS & NS & NB & NM & NM & NS & Z \\
PS & Z & NS & NM & NM & NS & NS & Z \\
Z & Z & NS & NS & NS & NS & NS & Z \\
PS & Z & Z & Z & Z & Z & Z & Z \\
PM & PB & PS & PS & PS & PS & PS & PB \\
PB & PB & PM & PM & PM & PS & PS & PB \\
\hline
\end{tabular}

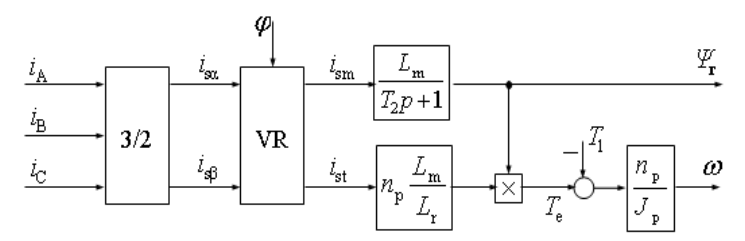

Figure 1. mathematical model of vector transformation and current decoupling of induction motor

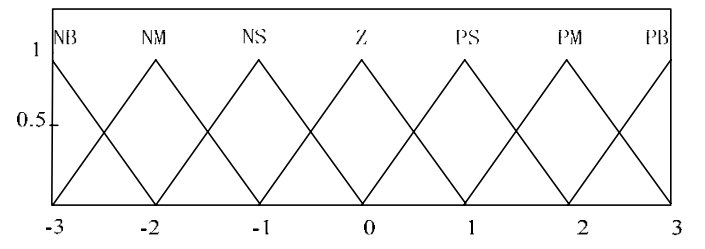

Figure 2. degree of membership function of e, ec, $\mathrm{Kp}, \mathrm{Ki}, \mathrm{Kd}$

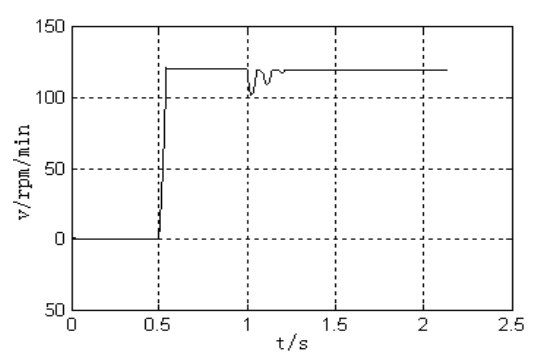

Figure 3. speed response curve of PI algorithm controller 


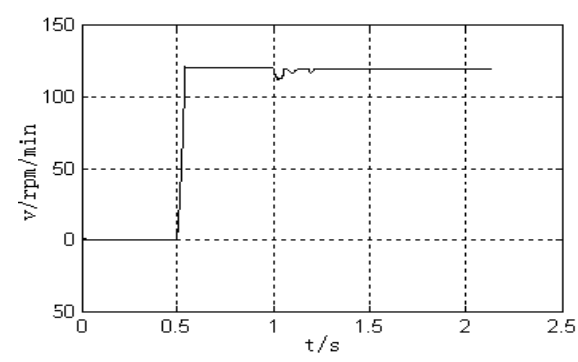

Figure 4. speed response curve of fuzzy PI algorithm controller

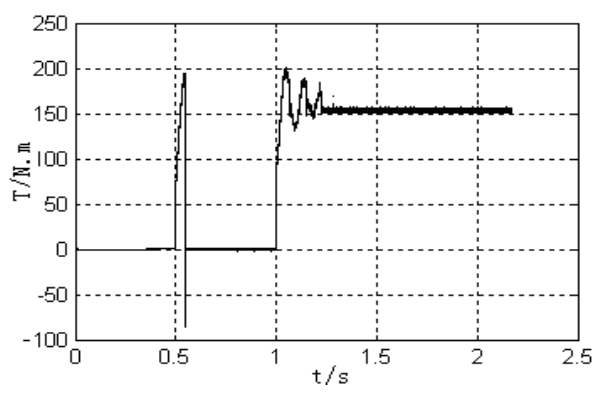

Figure 5. torque response curve of PI algorithm controller

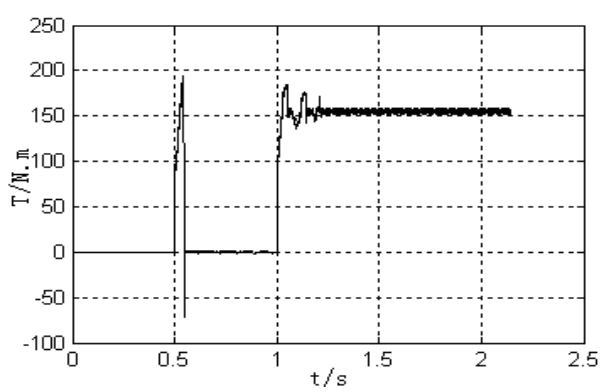

Figure 6. torque response curve of fuzzy PI algorithm controller 